\title{
Social inclusion implications of park-and-ride
}

\section{G. Parkhurst}

Park and ride (P\&R) schemes are often promoted as an efficient means of extending the effective catchment of public transport networks into car-dependent areas with low population densities, such as rural districts. However, using $\mathbf{P} \& \mathbf{R}$ typically requires the traveller to have access to a car. As car ownership is often used as an indicator of social inclusion, providing P\&R for motorists is not an obvious means of reducing exclusion from travel opportunities. Nonetheless, the present article argues that policies to promote interchange from cars to bus or rail can act as a force for either greater or less social exclusion, depending on who can access the services and what the alternative options would be in the absence of $P \& R$ being provided. The conditions under which inclusion is most likely to be promoted are reviewed. Key findings are that P\&R facilities should not be developed at the expense of investment in conventional public transport and that the services should not be exclusively aimed at motorists. A particular situation in which motorists on relatively low incomes might benefit from P\&R provision is where they would otherwise face high access charges to urban areas, in the form of road tolls or parking fees.

\section{THEORETICAL PERSPECTIVES ON TRANSPORT EXCLUSION APPLIED TO P\&R}

Two important themes underlie current debates on social exclusion. First, there is general agreement that the concept is not reducible to one of deprivation, underclass or marginalisation and, in particular, is not synonymous with poverty. ${ }^{1-3}$ Instead, an operational definition is that 'social exclusion is a process, which causes individuals or groups, who are geographically resident in a society, not to participate in the normal activities of citizens in that society'.

Second, a number of authors have noted that social justice considerations risk being overlooked due to the focus of transport policy on the tension between demands for economic growth and environmental protection. Green and Wegener ${ }^{5}$ observe that definitions of sustainable development emphasise the needs of future generations, but argue that social justiceboth at the national and international levels - must also be present for any definition of sustainability to be adequate. Feitelson ${ }^{6}$ suggests that social equity, economic development and environmental protection should be seen as the corners of an equilateral triangle with trade-offs between all three recognised.
On a cautionary note, however, not all commentators regard the concept of sustainability as capable of reform. Baeten (p. $70),{ }^{7}$ for example, referring to the topic of highway appraisal, argues that 'the harmonious and conflict-avoiding vocabulary of the sustainability agenda is unable to cope with material processes that shape and transform infrastructural networks.' The fear is that the relative position of excluded groups will not improve if the focus of sustainability policy is on maintaining the quality of life of the majority while reducing overall resource consumption-at least not unless there is a clear attempt to place wealth redistribution on the policy agenda.

\section{I.I. Exclusion mechanisms relevant to $\mathbf{P} \& \mathbf{R}$ schemes} Recently, attempts have been made to reduce the perceived limitations of sustainability concepts for exclusion and, more generally, to clarify the meaning of the concept of transport exclusion itself, by considering particular types of exclusion.

Feitelson ${ }^{6}$ notes that transport planning decisions, like all planning decisions, have direct effects on the environment, but observes that they have particularly high levels of indirect effect. These include pressures on land-use patterns and the creation of 'winners' (typically the users of new infrastructure) and 'losers' (most obviously those located near the infrastructure but unable to use it). Church et al. ${ }^{1}$ have identified seven broad mechanisms that can lead to exclusion: physical, geographical, distance, economic, time-based, fear-based and spatial. Kenyon et al. ${ }^{3}$ have extended this approach, placing mobility exclusion as a particularly important category among a total of nine. The other eight types of exclusion are economic, societal, social network, organised political, personal political, personal, living space and temporal. In addition to influencing access to social and economic opportunity, mobility exclusion also has the potential to reinforce these other dimensions of exclusion.

In the case of P\&R-considering the assessment of the exclusion implications of providing a particular kind of transport infrastructure, rather than transport exclusion in its entirety - the mobility dimension can be defined as whether the PER facility is present or not. This fact has a primary influence on exclusion. Secondarily, if a PAR is present, then the other types of exclusion have a potential influence over its accessibility; through economic exclusion (e.g. ability to pay for travel), temporal exclusion (e.g. time available to spend 
travelling), living space exclusion (e.g. freedom to move without fear for personal security), and personal political exclusion (e.g. liberty to determine own movement patterns). Finally, the other dimensions-personal exclusion and exclusion from social institutions and organised politics-will impact on the degree of influence an individual has over how resources are allocated to the transport and land-use planning system. Low levels of inclusion at this stage may result in decisions about infrastructure provision that increase other kinds of exclusion in the longer term.

\section{SOCIAL INCLUSION IMPLICATIONS OF P\&R SCHEMES}

Policies to enhance interchange, either between cars and buses or cars and rail (light, underground, suburban, or high-speed) have been promoted in the UK and other industrialised states for more than three decades now. Typically, in the UK, rail P\&R schemes have involved the provision of dedicated car parking capacity at existing railway stations, which is usually targeted at travellers making day-return trips and is made available either free of charge or at modest daily rates. A few stations have been promoted as parkway stations. These typically have high-frequency rail services, significant parking capacity (500 spaces upwards), and are located in areas where there are large numbers of potential rail users living beyond walking range of a station.

Bus-based schemes, instead, usually involve the provision not only of parking capacity-typically ranging between 500 and 1500 spaces - but also dedicated shuttle bus services. The car parks are typically up to $5 \mathrm{~km}$ from the town centres they serve. Local authorities that implement bus P\&R usually have aspirations to develop a ring of sites at the periphery, located on all or most of the principal inter-urban routes to the town.

The explicit and implicit aims of the particular schemes have varied considerably over time and between places, ${ }^{8}$ but include

(a) increasing the ridership of a public transport system by extending the area of the effective catchment

(b) supporting economic growth through increasing parking opportunities

(c) supporting economic growth by reducing congestion in the commercial centre of a town

(d) traffic reduction, by intercepting vehicle trips

(e) improving the journey quality for travellers who have limited way-finding experience with a particular area, or low tolerance of urban driving conditions.

Applying the dimensions identified by Kenyon et al., ${ }^{3}$ an initial appraisal of the inclusion implications of P\&R schemes suggests they have the potential to (a) increase access to mobility opportunities, but in many cases only for those with a car available

(b) reduce the costs of travel, ${ }^{9}$ potentially avoiding exclusion for a small group of travellers who can only just afford access to a car, while increasing the relative economic exclusion of those without access to a car

(c) reduce exclusion on temporal grounds, or at least to insulate travellers from increases in travel time, by giving access to public transport which benefits from a segregated right of way or on-street priorities

(d) increase living space exclusion experienced by communities immediately around the car parks.

The following subsections explore these potential effects in more detail.

\section{I. Influence of $\mathbf{P} \& \mathbf{R}$ on physical mobility opportunities}

Due to the flexibility of car use, P\&R provision will rarely broaden the range of destinations that are available to the motorist. The exception is perhaps the circumstance in which parking is not in sufficient supply at a particular destination to meet demands, so the availability of PCR can increase the number of trips to that destination that can be begun by car. However, if the parking is available on a first-come, first-served basis there is unlikely to be an exclusion implication among motorists, as each will have an equal opportunity to use it. (The level of any parking charges will have an effect, but this is considered below under economic exclusion.)

The implication for non-car users is harder to predict. Busbased P\&R is often provided as a separate service, specifically marketed to motorists as a superior, differentiated product with higher social status. Frequencies are often higher than can be achieved for conventional services, due to the high concentration of demand at relatively few stops, which enables efficient utilisation of resources. Given this competitive advantage, it is not surprising that bus-based schemes have been shown to attract a significant proportion of users from existing public transport services. Fig. 1 indicates the proportions of users of bus-based schemes in eight towns who can be regarded as abstracted from public transport. 


\begin{tabular}{|c|c|c|c|c|c|}
\hline \multirow{2}{*}{$\begin{array}{l}\text { Case-study } \\
\text { town }\end{array}$} & \multicolumn{4}{|c|}{ Proportion of all users who: } & \multirow{2}{*}{$\begin{array}{l}\text { Average length of } \\
\text { return car trip to } \\
\text { site: } \mathrm{km}\end{array}$} \\
\hline & $\begin{array}{l}\text { Would use } \\
\text { public transport } \\
\text { as alternative }\end{array}$ & $\begin{array}{c}\text { Walked or cycled } \\
\text { to a site }\end{array}$ & $\begin{array}{l}\text { Parked but would } \\
\text { use public transport } \\
\text { as alternative: } \\
\text { min. estimate }\end{array}$ & $\begin{array}{l}\text { Parked but would } \\
\text { drive to destination } \\
\text { as alternative: } \\
\text { max. estimate }\end{array}$ & \\
\hline Brighton & 0.41 & $0 \cdot 31$ & $0 \cdot 10$ & $0 \cdot 17$ & $6 \cdot 6$ \\
\hline Cambridge & $0 \cdot 24$ & 0.07 & $0 \cdot 17$ & $0 \cdot 35$ & $16 \cdot 0$ \\
\hline Coventry & 0.21 & 0.05 & $0 \cdot 16$ & 0.46 & $9 \cdot 8$ \\
\hline Norwich & $0 \cdot 29$ & 0.02 & $0 \cdot 27$ & 0.43 & $32 \cdot 7$ \\
\hline Plymouth & $0 \cdot 32$ & $0 \cdot 10$ & $0 \cdot 22$ & 0.45 & 14.8 \\
\hline Reading & $0 \cdot 31$ & 0.08 & 0.23 & 0.43 & $11 \cdot 2$ \\
\hline Shrewsbury & $0 \cdot 18$ & 0.04 & 0.14 & 0.59 & $19 \cdot 7$ \\
\hline York & 0.26 & $0 \cdot 20$ & 0.06 & $0 \cdot 48$ & $30 \cdot 5$ \\
\hline
\end{tabular}

Although travellers with a car available can take advantage of these superior services, they are often difficult for non-car travellers to access. The sites are often located on the edge of urban areas, not within convenient walking distance for most travellers, or are without attractive, safe, walking routes for those whose origins are within range. Table 1 demonstrates generally low rates of walking and cycling to P\&R sites; the notable exceptions have been recorded in Brighton and York, where sites are embedded within residential areas.

In the case of rail P\&R, railheading may be encouraged. This occurs when travellers drive along a rail corridor in order to access rail services at a point that is more favourable in price or service quality terms than joining the system at the nearest point to their origins. It is not stimulated solely by official P\&R, but capacity provision could encourage that effect. In these cases, the branch line railways or rural bus routes that already have lower service frequencies may lose patronage to the trunk routes, with the possible consequence of a further downward spiral in service levels.

\section{2. $P \& R$ and economic exclusion}

Ideally, P\&R will be provided in such a way that access trips contribute additional patronage to an existing service, as usually occurs in the case of rail-based schemes. Further, the ideal scheme would not result in the abstraction of significant amounts of passenger-km. Hence, there would be indirect benefits to non-motorists, in terms of lower ticket prices, due to the greater number of travellers and greater system efficiency. In this way, economic exclusion may be reduced through lower public transport travel costs.

In practice, however, many bus-based dedicated schemes have been subsidised to create user-charges significantly below market rates, through low fares and free parking. The subsidies are provided variously

(a) to overcome the availability to some car users of free parking near the destination

(b) or because commercially available car parking is offered at low cost

(c) and/or in reflection of a possible traffic reduction benefit for some individuals, businesses and other organisations due to lower travel costs.

In contrast, under current UK legislation, subsidies cannot be provided for commercially operated bus services, which are set at a market rate based on what travellers - many of whom are public transport dependent-are prepared to pay to reach employment and vital services. Subsidies can be paid for services that are not commercially viable, but fares for these services are typically at least as high as for commercial services.

As a result of subsidies, using a dedicated P\&R service may become the cheapest travel option to those with a car available; cheaper than driving to the urban centre and paying for parking, and cheaper than using public transport for the whole journey. W S Atkins ${ }^{10}$ found that, for 18 dedicated P\&R bus services, the conventional service sharing the same corridor was more expensive in 16 cases. Further analysis of the figures shows that a passenger would have to pay on average $68 \%$ more to use the conventional service.

Furthermore, some schemes, including those in Norwich and Reading, have allowed up to seven adults travelling in the same car to travel for one fare on the PCR service-approximately the cost of one adult return ticket. In some cases where group discounts are available, measures have been implemented to prevent travellers who do not park a car at the site from joining the bus. In others, car travellers who do not park a car can take advantage of the discount, and this explains a proportion of the abstraction from public transport observed in Fig. 1. On average, though, at least two-thirds of those abstracted by P\&R from public transport did drive cars to the sites at the eight towns (Table 1).

Hence, where subsidies are provided, the effect is to reinforce the efficiency advantages of PAR discussed above, adding to the motivations for travellers with cars available to switch mode of travel from conventional public transport. In some cases subsidies are partly offset by developer contributions, or by using revenues from local-authority-operated car parks in the urban area, although these accounting procedures may still represent an opportunity cost for other local authority services. 
In other cases revenue support is funded from local taxation. Particularly where the district tier of local government provides a scheme, this may result in the residents of an urban area, some of whom may be economically excluded, funding a subsidised P\&R scheme which they themselves cannot use, as it is designed to be attractive to relatively wealthy visitors to the urban area.

There are a number of mechanisms, then, by which PER schemes targeted solely at - or in practice useable only bymotorists can result in increased economic exclusion.

(a) P\&R may offer a service that is available only to car users.

(b) P\&R user costs may be lower, distorting the travel market and resulting in mode switching from public transport, risking higher fares for those unable to switch, greater dependence on local authority support and, ultimately, the withdrawal of non-P\&R routes.

(c) P\&R schemes are resource-intensive and consume funds which could have been spent on other transport-sector projects, or other public services.

In contrast are the cases in which the costs for car travel to town centres are increased with the aim of reducing traffic and congestion. For example, the introduction of tolls, as in Durham and London, may create a case for providing P\&R to avoid economic exclusion resulting from some motorists' inability to afford the higher access costs of visiting the charged area. Although relatively few of the most economically excluded members of society have access to a car, caution has been urged in the use of car ownership as an indicator of wealth in rural contexts. ${ }^{12}$ 'Enforced' ownership may occur due to the remoteness of an individual's residential location, at the expense of other quality-of-life aspects.

Stokes ${ }^{13}$ has provided an estimate of the extent of higher car ownership in rural areas. He notes that more than $60 \%$ of households in the lowest-income quintile and living in the largest urban areas are without a car, while the same number of equivalent households in rural areas do have at least one car.

These data are suggestive of the existence of a group who feel obliged to own cars despite having to make sacrifices elsewhere in their household budgets. In turn, this implies that some households might experience economic and mobility exclusion as a result of higher charges for accessing a town on which they are dependent for goods and services.

\subsection{Temporal exclusion}

In the same way that PER provision may reduce mobility and economic exclusion for car users who can be regarded as excluded, the opportunity to interchange may reduce temporal exclusion. A reduction in exclusion resulting from shorter journey times may result if P\&R makes travel by rail or some other segregated, high-speed network accessible. This would be dependent, though, on the travel opportunity being inclusive in other terms-in particular, having affordable fares.

Theoretically, there may also be benefits for temporally excluded non-users. In practice, P\&R schemes often redistribute or increase traffic overall. ${ }^{11,14}$ Nonetheless, there may be traffic reduction at particular congestion hotspots, with the result of faster journey times by both bus and car. Moreover, if the reduction in traffic is combined with the reallocation of road space through the introduction of bus priorities, then P\&R is more likely to result, indirectly, in faster journey times for bus passengers, a group in which the temporally excluded are likely to be well represented.

\subsection{Living space/environmental exclusion}

Transport activities result in emissions of air pollution and noise and visual intrusion, over wide areas. In consequence, many citizens who would normally be regarded as socially included may nonetheless be excluded from enjoying acceptable standards of living environment. Large P\&R schemes, which are usually bus-based, have considerable local environmental consequences in terms of land take, visual intrusion, pollutant runoff, and security lighting. They also affect the quantity and distribution of traffic in the locale. They may attract car-related crime, including theft, vandalism, arson and abandonment, which may increase the perception that an area has a crime problem. Overall, the construction of P\&R in a particular place is usually justified in terms of a trade-off between benefits to travellers and environmental conditions in the urban area overall and a poorer environment in the immediate environs of the site.

\subsection{A product of political exclusion?}

It has been argued above that the provision of P\&R can sometimes benefit excluded travellers with a car available and sometimes indirectly benefit those without access to a car. Nonetheless, the main motivations behind P\&R provision reflect the interests of the majority group of citizens who do have access to a car, and are not excluded from society. Politicians and planners often argue that it is necessary to increase the facilities available for this group, often in order to make modest changes to the cost of car use and the amount of roadspace made available for motorists. These beliefs reflect the influential and powerful position of motorists, and the car, in policy making.

Hence, as well as having exclusion implications, PAR can be seen as resulting from a planning process which excludes many citizens because they are outside organised politics, do not take part in consultations and have little effective influence on planning outcomes. As residents' groups and pressure groups such as the Council for the Protection of Rural England are often relatively included in the political process, this creates another source of risk to the excluded; that such groups will succeed in protecting sites they perceive as having high environmental values, so increasing the likelihood that P\&R sites will be located in or near residential areas with high levels of excluded households.

\section{CONDITIONS UNDER WHICH P\&R IS MOST LIKELY TO INCREASE SOCIAL INCLUSION}

The foregoing analysis suggests the following factors are likely to maximise the social inclusion value of P\&R schemes in most cases

(a) parking provision integrated within public transport networks that are accessible to all traveller groups

(b) location of P\&R in places and at distances from the destination that are likely to result in significant traffic 


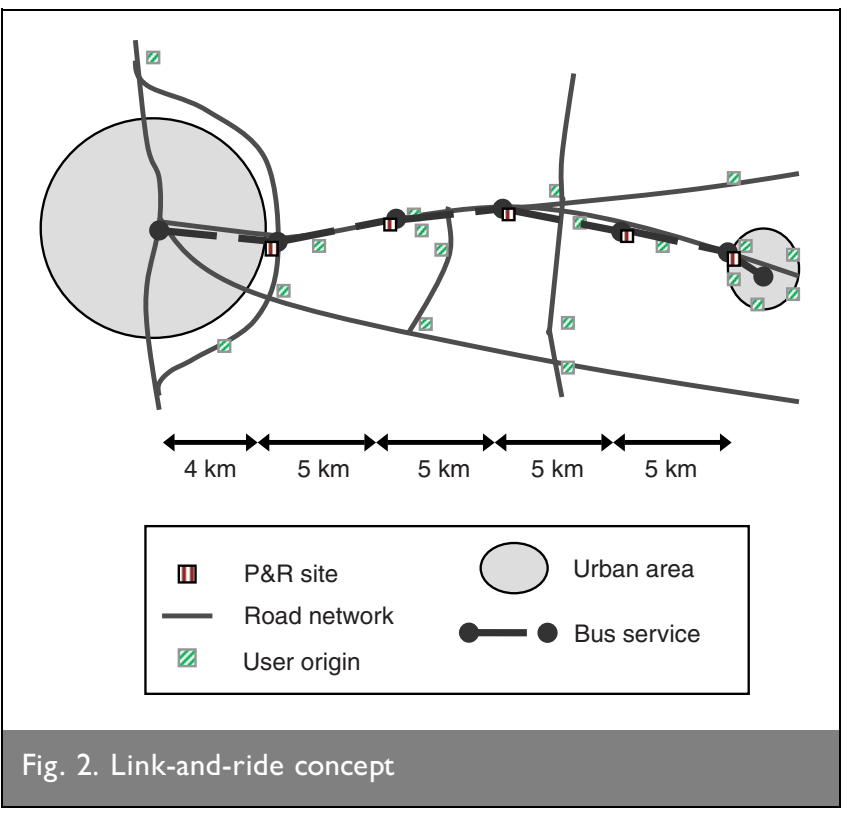

reduction and that can in turn offer traffic congestion reduction benefits to public transport services

(c) careful integration of PEtR capacity provision with corridor-length road-space reallocation measures to ensure any travel-time reduction benefits are enjoyed by non-users as well as users

(d) user charges levied at market rates, or at least not undercutting the overall money costs of walk-to-publictransport travel

(e) location near users' origins, to minimise the amounts that low-income but car-dependent travellers need to spend on car use

( $f$ ) location near users' origins so that any environmental costs are more likely to be borne by beneficiaries

(g) small-scale sites to minimise the potential for living-space exclusion resulting from a deterioration in environmental standards

(h) consultation with all affected groups when planning P\&R, and considering the full range of travel needs, so maximising political inclusion.

Parkhurst ${ }^{14}$ has proposed 'link-and-ride' as an alternative to bus-based PAR located at the edge of urban areas, which meets many of the above criteria (Fig. 2). Additionally, the approach has been predicted to reduce, rather than increase, overall car traffic and have lower environmental consequences. ${ }^{15}$

\section{I. Progress towards more socially inclusive $\mathbf{P} \& \mathbf{R}$ schemes}

A number of established or emerging P\&R strategies show enhanced performance against the 'social-inclusion-proofing' criteria noted above. The relative costs of car and public transport use for travel to the urban centre emerge as a critical factor in promoting inclusion.

In order to pay for enhanced security at 0xford sites, user costs were increased towards the market rate in 1997-1998, through the introduction of a fee for parking in addition to a bus fare. Use of the Redbridge site subsequently fell. Simultaneously, the bus company operating the Abingdon-0xford limited-stop X3 express service, which does not have an official P\&R oppor-

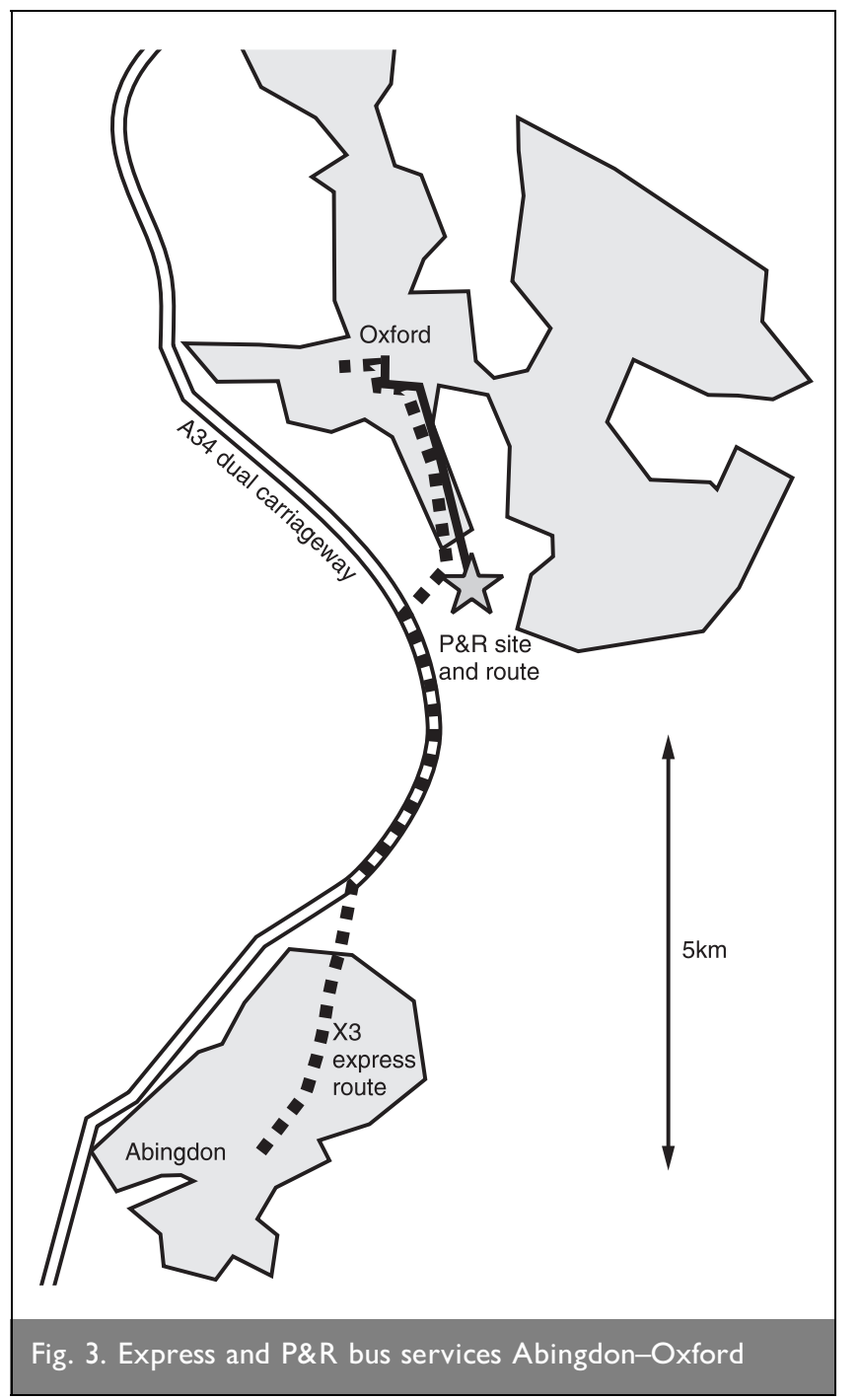

tunity, observed a notable growth in patronage on the $10 \mathrm{~km}$ route (Fig. 3). This change resulted in the reduction of capacity restraints at Redbridge and perhaps a lower future requirement for local authority subsidy, while supporting the enhancement of the non-P\&R bus route. The bus company believed that mode switches were a significant factor explaining patronage growth on the X3 route. ${ }^{16}$ Notably, a commuter at that time paid from $£ 1 \cdot 70$ per day for travel on the $\mathrm{X} 3$, while the Redbridge parking charge plus bus fare was £1.35 per day. However, travellers using the $\mathrm{X} 3$ instead of P\&R would have saved petrol costs of around $£ 1$ per day.

In Scotland, the Ferrytoll P\&R service which links Fife with Edinburgh and Livingston operates at a relatively long range and is integrated with established bus services. One 500-space PEtR site is available, located to the north of the Forth Road Bridge and $20 \mathrm{~km}$ from Edinburgh (Fig. 4). The bus service has been provided by creating an additional stop on Fife-Lothian bus routes, which are mainly express services.

Introduction of P\&R has contributed to the justification for additional public transport priorities on the A90 between the bridge and Edinburgh. Initial monitoring suggested that around half of the P\&R users had travelled by car to their destinations prior to using the service. Most of the rest had switched from other public transport services, in particular rail. Given that 


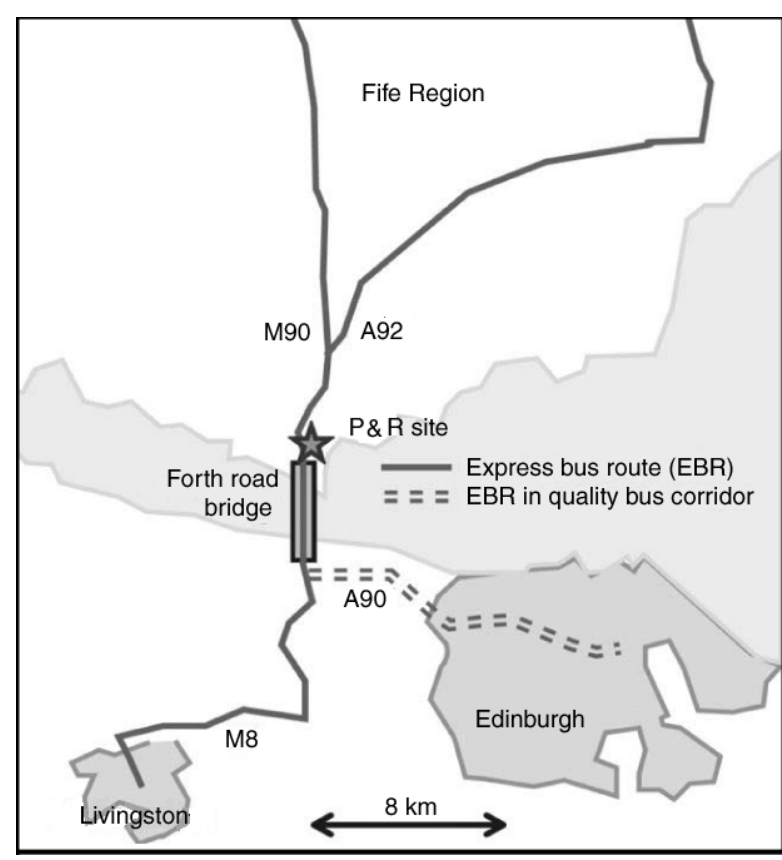

Fig. 4. Ferrytoll P\&R with bus routes to Edinburgh and Livingston

these rail services were suffering from overcrowding at peak times, ${ }^{17}$ this modal shift is unlikely to have threatened service viability. Overall, the transfer of relatively long car trips is likely to have increased bus patronage and reduced car traffic, despite some walking trips to access public transport subsequently being made by car.

Another PEtR service integrated with a conventional bus service was begun in Bristol in 2002, although this is not associated with a bridge toll. The Portway site is located on the A4, $8 \mathrm{~km}$ to the north-west of the city centre. As it has around 250 parking spaces, it would not be viable in patronage terms if not part of a 'quality bus' route serving communities on the north bank of the River Avon.

Greater Manchester Passenger Transport Executive (GMPTE) is promoting a scheme that corresponds closely to the link-and- ride concept. The Leigh-Salford-Manchester Quality Bus Corridor initiative covers approximately 19 route-km. As part of the project, GMPTE proposes to bypass the western section of this corridor with an $8 \mathrm{~km}$ guided busway featuring seven stops on the guideway itself. At three of these there would also be provision for PetR, amounting to 170 spaces total capacity. Additionally, a 270-space site may be developed in the unguided section of the corridor, adjacent to Junction 14 of the M62 (Fig. 5).

The scheme is being promoted with the reduction of mobility exclusion as a key aim. Trips from Leigh to central Manchester by bus, or by bus interchanging to rail, currently take 50-75 minutes, while the busway is forecast to increase service reliability and reduce journey times to around 40 minutes, thereby saving public transport passengers 20-70 minutes per return trip. ${ }^{18}$ The provision of P\&R capacity on the guideway has two motivations: to encourage car users living beyond walk range to convert the majority of their journeys to public transport and to avoid informal P\&R behaviour, which, in the absence of official provision, might be expected to emerge in residential streets near the stops.

\section{CONCLUSIONS}

Investments in P\&R have the effect of increasing the infrastructure provision and travel opportunities available for car use. Hence, the situations in which they directly reduce social exclusion are likely to be limited to those in which cardependent motorists would otherwise be unable to afford sufficient mobility so as to take a full part in society. Indeed, to the extent that the funds spent on P\&R are part of a 'zero-sum game', there will be fewer funds for the other projects, which may have been more likely to reduce exclusion. Furthermore, PCtR schemes which are not designed with the need to reduce exclusion as a priority can result in abstraction from public transport and traffic growth outside the urban area, both of which phenomena may leave the viability of public transport services more marginal. The quality of environment around the sites may be reduced, and those bearing these environmental costs may feel increased exclusion from the planning process.

In contrast, there is the potential for well-designed schemes to reduce exclusion, provided that they are integrated with

existing services both physically and in terms of the relative travel costs. Consideration of a number of dimensions of social exclusion suggests that P\&R capacity needs to be provided in small-scale units and relatively near users' origins for this objective to be promoted.

\section{REFERENCES}

1. Church A., Frost M. and Suluivan K. Transport and social exclusion in London. Transport Policy, 2000, 7, No. 3, 195-205.

2. Social Exclusion Unit. 
Making the Connections: Transport and Social Exclusion. UK Government Cabinet Office, London, 2002.

3. KenYon S., Lyons G. and RafFerTy J. Transport and social exclusion: investigating the possibility of promoting inclusion through virtual mobility. Journal of Transport Geography, 2002, 10, No. 3, 207-2 19.

4. GAFFRON P., HinE J. P. and Mitchell F. The Role of Transpor in Social Exclusion in Urban Scotland: Literature Review.

Scottish Executive Central Research Unit, Edinburgh, 2001.

5. GREENE D. L. and WeGENER M.. Sustainable transport. Journal of Transport Geography, 1997, 5, No. 3, 177-190.

6. FeITELSON E. Introducing environmental equity dimensions into the sustainable transport discourse: issue and pitfalls. Transportation Research D, 2002, 7, 99-118.

7. BAETEN G. The tragedy of the highway: empowerment, disempowerment and the politics of sustainability discourses and practices. European Planning Studies, 2000, 8 , No. 1, 69-86.

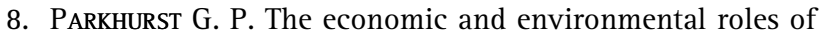
park and ride. Proceedings of the 6th Annual PTRC Conference on Park and Ride. PTRC, London, 1998.

9. PARKhURST G. P. Park and ride: could it lead to an increase in car traffic? Transport Policy, 1995, 2, No. 1, 15-23.

10. HARris C., COOPER B. and WhitField S. The Travel Effects of Park and Ride. W S Atkins Planning Consultants, Epsom for DETR, 1998.
11. PARKhURSt G. P. Influence of bus-based park and ride facilities on users' car traffic. Transport Policy, 2000, 7, No. 2, 159-172.

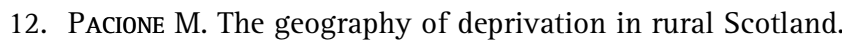
Transactions of the Institute of British Geographers, 1995, 20, No. 2, 173-192.

13. SтокеS G. Reducing reliance on the car in rural areas. Proceedings of the Association of European Transport Conference, Seminar on Managing Demand and Creating Alternatives in Cities, PTRC, London, 2002.

14. PARKhURST G. P. Link-and-ride-a longer-range strategy for car-bus interchange. Traffic Engineering and Control, 2000, September, 319-324.

15. PARKhURSt G. P. and Richardson J. Modal integration of bus and car in UK local transport policy: the case for strategic environmental assessment. Journal of Transport Geography, 2002, 10, No. 3, 195-206.

16. RADLEY J. Personal communication from former Marketing Manager, Oxford Bus Company, April 2000.

17. KinNAIRD D. Pers. comm. Transportation Marketing \& Information, Fife Council, October 2001.

18. Greater Manchester Passenger Transport Executive. The Greater Manchester (Leigh Busway) Order. Statement of Case under Transport and Works Act 1992. GMPTE, Manchester.

Please email, fax or post your discussion contributions to the secretary by I December 2003: email: kathleen.hollow@ice.org.uk; fax: +44 (0)20 7799 1325; or post to Kathleen Hollow, Journals Department, Institution of Civil Engineers, I-7 Great George Street, London SWIP 3AA. 